\title{
Association Between Metformin Initiation and Incident Dementia Among African American and White Veterans Health Administration Patients
}

\author{
Jeffrey F. Scherrer, $\mathrm{PbD}^{1,2}$ \\ Jobn E. Morley, $\mathrm{MBBCb}^{3}$ \\ Joanne Salas, $\mathrm{MPH}^{1,2}$ \\ James S. Floyd, $M D^{4-6}$ \\ Susan A. Farr, $\mathrm{PbD}^{3,7}$ \\ Sascha Dublin, $M D^{4,8}$ \\ 'Department of Family and Community \\ Medicine, Saint Louis University School \\ of Medicine, St Louis, Missouri \\ ${ }^{2}$ Harry S. Truman Veterans Administra- \\ tion Medical Center, Research Service, \\ Columbia, Missouri \\ ${ }^{3}$ Division of Geriatric Medicine, Saint \\ Louis University School of Medicine, \\ St Louis, Missouri \\ ${ }^{4}$ Department of Epidemiology, University \\ of Washington, Seattle, Washington \\ ${ }^{5}$ Department of Medicine, University \\ of Washington, Seattle, Washington \\ ${ }^{6}$ Cardiovascular Health Research Unit, \\ University of Washington, Seattle, \\ Washington \\ ${ }^{7}$ Saint Louis Veterans Affairs Medical \\ Center, Research Service, John Cochran \\ Division, St Louis, Missouri \\ ${ }^{8}$ Kaiser Permanente Washington Health \\ Research Institute, Seattle, Washington
}

Conflicts of interest: authors report none.

\section{CORRESPONDING AUTHOR}

Jeffrey F. Scherrer, PhD

Family and Community Medicine

Saint Louis University School of Medicine 1402 S Grand Blvd

St Louis, MO 63104

jeffrey.scherrer@health.slu.edu

\begin{abstract}
PURPOSE African American patients are more likely to experience cognitive decline after type 2 diabetes mellitus onset than white patients. Metformin use has been associated with a lower risk of dementia compared with sulfonylureas. Evidence for whether this association differs by race is sparse.

METHODS Veterans Health Administration (VHA) medical record data were obtained for 73,761 African American and white patients aged $\geq 50$ years who used the VHA from fiscal years 2000 to 2015. Patients were free of dementia and diabetes medications during fiscal years 2000 and 2001 and subsequently initiated metformin or sulfonylurea monotherapy. For race and age subgroups, Cox proportional hazards models using propensity scores and inverse probability of treatment weighting to control for confounding were computed to measure the association between metformin vs sulfonylurea initiation and incident dementia.

RESULTS After controlling for confounding, among patients aged $\geq 50$ years, metformin vs sulfonylurea use was associated with a significantly lower risk of dementia in African American patients (hazard ratio $[\mathrm{HR}]=0.73 ; 95 \% \mathrm{Cl}$, 0.6 0.89 ) but not white patients ( $\mathrm{HR}=0.96 ; 95 \% \mathrm{Cl}, 0.9-1.03)$. The strongest magnitude of association between metformin and dementia was observed among African American patients aged 50 to 64 years $(\mathrm{HR}=0.6 ; 95 \% \mathrm{Cl}, 0.45-0.81)$. Among those aged 65 to 74 years, metformin was significantly associated with lower risk of dementia in both races. Metformin was not associated with dementia in patients aged $\geq 75$ years.
\end{abstract}

CONCLUSIONS Metformin vs sulfonylurea initiation was associated with a substantially lower risk of dementia among younger African American patients. These results may point to a novel approach for reducing the risk of dementia in African Americans with type 2 diabetes mellitus.

Ann Fam Med 2019;17:352-362. https://doi.org/10.1370/afm.2415.

\section{INTRODUCTION}

Cype 2 diabetes mellitus (T2DM) is almost twice as prevalent among African Americans as non-Hispanic whites. The age-adjusted prevalence of T2DM is $13.4 \%$ in African Americans and $7.3 \%$ in whites. ${ }^{1}$ African American patients on average have worse glycemic control $^{2}$ and more diabetes-related complications than white patients. ${ }^{3,4}$

Diabetes is a risk factor for dementia, ${ }^{5}$ and African Americans have nearly twice the incidence of dementia as whites. ${ }^{6,7}$ This disparity is greater in patients aged 55 to 65 years compared with older patients. ${ }^{8}$ The prevalence of dementia in patients with T2DM is $10 \%$ to $18 \%$ greater in African American patients compared with white patients. ${ }^{9}$ Results from the Atherosclerosis Risk in Communities study indicate that African American participants with T2DM had a $41 \%$ decrease in cognitive test scores over a period of 14 years, whereas white participants experienced no decrease. ${ }^{10}$

Emerging evidence from observational studies with robust control for confounding suggests that a first-line diabetes medication, metformin, 
compared with sulfonylureas, is associated with an $8 \%$ to $10 \%$ decrease in dementia risk. ${ }^{11,12}$ We are aware of 1 study that evaluated differences in the association between metformin and dementia between white and African American patients. ${ }^{11}$ Among patients aged 65 to 74 years, metformin was significantly associated with lower dementia risk in white patients (hazard ratio $[\mathrm{HR}]=0.87 ; 95 \% \mathrm{CI}, 0.77-0.99)$ but not in African American patients ( $\mathrm{HR}=0.95 ; 95 \% \mathrm{CI}, 0.66-1.38)$. That study did not include patients aged $<65$ years, and the findings might not apply to younger patients. The increased risk of cognitive decline in African Americans compared with whites is greatest in younger age groups (ie, a ged 55 to 64 years $^{8}$ ), and African Americans are more likely than whites to experience diabetes onset before age $50 .{ }^{13}$ Assuming metformin mitigates diabetes-related cognitive decline, the protective effects of metformin might be observed in younger patients not included in existing research.

The present study was designed to (1) determine if initiation of metformin, compared with sulfonylureas, is associated with a lower risk of dementia among white and African American patients aged $\geq 50$ years, (2) determine if results change after controlling for glycemic burden or hypoglycemic events, and (3) evaluate drug associations with incident dementia in race and age subgroups.

\section{METHODS}

This study was approved, with a waiver of consent, by the institutional review boards of the participating institutions. We conducted a retrospective cohort study using a new-user design to examine outcomes after a new metformin prescription fill vs an active comparator, a new sulfonylurea prescription fill. Patient medical record data were obtained from the Veterans Health Administration (VHA) for fiscal years (FY) 2000 to 2015 (ie, October 1, 1999 to September 30, 2015) and included International Classification of Diseases, Ninth Revision, Clinical Modification (ICD-9-CM) diagnoses, prescription fills, laboratory results, vital signs, and demographic data. The VHA data included all VHA medical centers in the United States, and VHA-linked Medicare claims were used to obtain ICD-9-CM codes for care provided outside the VHA. Medicare Part-D pharmacy claims were available for only a subset of observation years and thus were not used to measure prescription fills.

For all VHA patients with $\geq 1$ encounter from October 1, 1999 to September 30, 2015 (FY 2000-2015), we selected patients with $\geq 1$ yearly visit in the 2 -year washout period (FY 2000-2001) and $\geq 1$ follow-up visit (FY 2002-2015). We excluded patients with a diagnosis of dementia or prescription fill(s) for dementia medication (donepezil, rivastigmine, galantamine, memantine) or antidiabetic medications in the washout period. Therefore, at baseline, patients had no documented evidence of dementia or of treatment for T2DM.

Patients were eligible if their first antidiabetic medication fill during follow-up was for metformin or sulfonylurea monotherapy and their medication start date occurred before October 1, 2012 (to allow for a minimum of 3 years of follow-up after prescription fill). Patients with dementia onset after washout and before metformin or sulfonylurea prescription fill were excluded. Patients had to have a hemoglobin $A_{1 c}$ $\left(\mathrm{HbA}_{\mathrm{lc}}\right)$ and a creatinine measurement, used in making the decision to prescribe medication, in the year before metformin or sulfonylurea prescription fill. In the year before metformin or sulfonylurea prescription fill, men with a creatinine value $\geq 1.5 \mathrm{mg} / \mathrm{dL}$ and women with a creatinine value $\geq 1.4 \mathrm{mg} / \mathrm{dL}$ were excluded because this was a contraindication for metformin use during the study observation period. To allow for a duration of drug exposure that could plausibly be associated with dementia risk, we excluded patients with no more than 90 days of follow-up after their first metformin or sulfonylurea prescription fill. Patients with missing demographic data were excluded. The sample was then limited to white and African American patients, resulting in a final analytic sample of 73,761 unique patients. The sample selection diagram is shown in Figure 1.

\section{Predictor Variable}

All variable definitions are shown in Supplemental Appendix 1 (http://www.annfammed.org/content/17/4/352/suppl/DC1). Metformin or sulfonylurea use was defined as a prescription fill at any dose and duration for metformin, acetohexamide, chlorpropamide, glimepiride, glipizide, glyburide, tolazamide, or tolbutamide.

\section{Outcome Variable}

Dementia was defined as $\geq 2$ ICD-9-CM diagnostic codes in any 12 -month period from inpatient, outpatient, or Medicare data. The date of the first diagnostic code was the dementia onset date.

\section{Confounding}

Potential confounders were measured from October 1, 1999 to the start of metformin or sulfonylurea use. Potential confounders included $\mathrm{HbA}_{1 \mathrm{c}}$ and creatinine values nearest to and within 12 months of metformin or sulfonylurea initiation. We controlled for diabetes complications (neuropathy, retinopathy, nephropathy), hypertension, hyperlipidemia, stroke or cerebrovascular disease, ischemic heart disease, congestive 


\section{Figure 1. Veterans Health Administration eligibility criteria.}

$2,311,519$ Yearly outpatient visit in FY 2000 \&

FY $2001 \&$ aged $\geq 50$ years at start of FY 2002

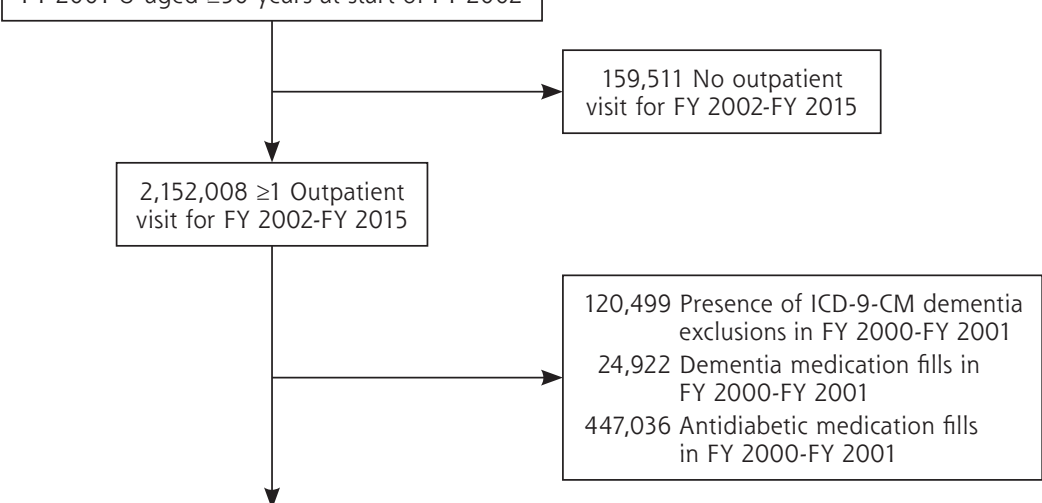

$1,600,099$ Free of dementia and antidiabetic medications in FY 2000-FY 2001

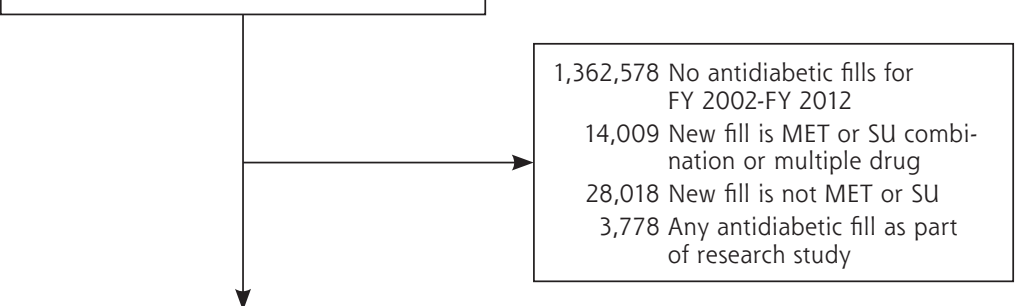

193,457 New antidiabetic fill for only MET or SU for FY 2002-FY 2012

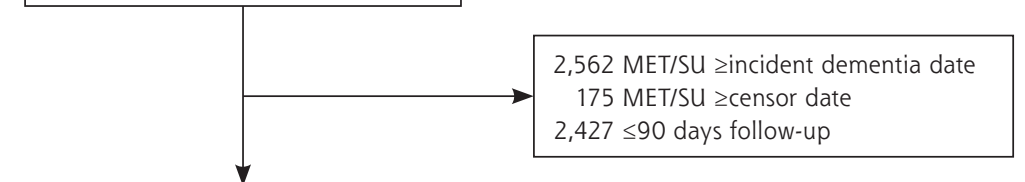

188,293 MET/SU date < dementia onset or censor date and $>90$ days follow-up

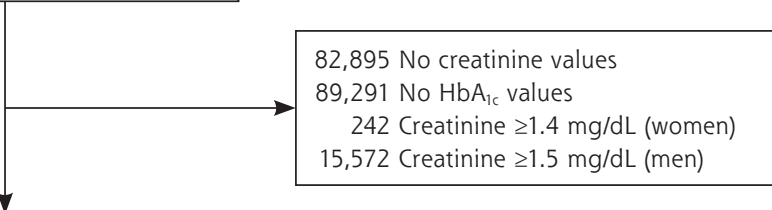

$77,857 \mathrm{HbA}_{1 \mathrm{c}}$ available and creatinine

$<1.4 \mathrm{mg} / \mathrm{dL}$ for women or $<1.5 \mathrm{mg} / \mathrm{dL}$ for men in year before MET/SU
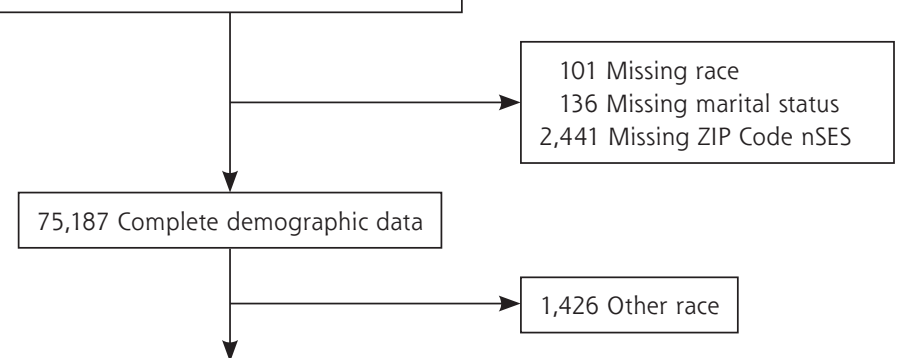

73,761 African American or white race

$\mathrm{FY}=$ fiscal year; $\mathrm{HbA}_{\mathrm{lc}}=$ hemoglobin $\mathrm{A}_{\mathrm{lc}}$ ICD-9-CM = International Classification of Diseases, Ninth Revision, Clinical Modification; MET = metformin; $\mathrm{nSES}=$ neighborhood socioeconomic status; $\mathrm{SU}=$ sulfonylurea. heart failure, atrial fibrillation or flutter, traumatic brain injury, vitamin B12 deficiency, and obesity. We also controlled for psychiatric disorders associated with increased risk of dementia. ${ }^{14}$ These included depression, bipolar disorder, schizophrenia, posttraumatic stress disorder (PTSD), and a composite anxiety disorder variable that included panic disorder, social phobia, obsessive compulsive disorder, generalized anxiety disorder, and anxiety disorder not otherwise specified. We controlled for alcohol abuse/dependence, illicit drug abuse/dependence, and nicotine dependence/smoking.

To address potential detection bias (ie, that patients who use more health care in general are more likely to be diagnosed with a condition of interest such as dementia), volume of health care use was calculated from the distribution of the average number of outpatient visits per month from first visit during the observation period to metformin or sulfonylurea start date. The top 25th percentile of the distribution was defined as high use, and the bottom 75 th percentile was defined as not high use.

We controlled for exposure to anticholinergic medications, nonsteroidal anti-inflammatory drugs (NSAIDs), statins, and antihypertensives because they might confound the association between antidiabetic medication and incident dementia. Exposure to these medications was defined as having 2 fills in any 6 -month period before metformin or sulfonylurea prescription fill.

Sociodemographic variables included age, sex, and marital status using the values nearest to and before metformin or sulfonylurea prescription fill. To control for use of non-VHA care, we measured access to VHA health 
insurance only vs VHA insurance plus other health insurance. We controlled for neighborhood socioeconomic status $\left(\mathrm{nSES}^{15}\right)$ using Census-level data tied to ZIP Code nearest to or on the date of metformin or sulfonylurea initiation. The nSES index score was calculated and a binary variable created from the sample measuring the top 50th percentile vs the lower 50th percentile nSES. Finally, because metformin and sulfonylurea prescribing rates have changed over time, we controlled for year of prescription fill.

\section{Propensity Scores and Inverse Probability of Treatment Weighting}

The propensity score (PS), estimated from a binary logistic regression model, was the probability of initiating metformin, rather than a sulfonylurea, given baseline covariates. For each patient, the PS was used to calculate a stabilized weight ${ }_{1}^{16,17}$ which is the marginal probability of receiving a metformin prescription fill divided by the PS for a metformin fill or (1 - marginal probability of metformin fill) divided by $(1-P S)$ for a sulfonylurea fill. Stabilized weights were trimmed if they were $\geq 10$ because well-behaved weights have a mean close to 1 and a maximum of $<10 .^{17,18}$ Stabilizing weights improves the precision of effect estimates by reducing variance of the weights. Inverse probability of treatment weighting generates a pseudopopulation in which confounding by measured characteristics is controlled when an adequate balance of variables, indicated by a standardized mean difference (SMD) of $<10 \%,{ }^{18,19}$ is observed between those receiving a metformin vs a sulfonylurea prescription fill.

\section{Analytic Approach}

Race-stratified, bivariate analyses estimated the association between potential confounders and metformin or sulfonylurea prescription fill using $\chi^{2}$ tests for categorical variables and independent samples $t$ tests for continuous variables. Poisson regression models were computed with unweighted data to calculate dementia incidence rates (per 1,000 person-years [PY]).

The association between receipt of a metformin prescription fill, compared with a sulfonylurea prescription fill, and incident dementia was estimated using racestratified Cox proportional hazards models computed with unweighted and weighted data. Follow-up time was defined as days from date of metformin or sulfonylurea prescription fill until dementia or censoring. Patients were censored at the time of the last available inpatient or outpatient VHA encounter or Medicare claim date.

A drug * race interaction term assessed whether estimates were different between races. Models were stratified by age (50-64, 65-74, $\geq 75$ years) within race. A drug * age interaction term assessed whether effect modification was present by age within each race. Results were expressed as HR and 95\% CI. Robust, sandwich-type variance estimators were used to calculate CIs and $P$ values for weighted data.

Cox proportional hazards models using weighted data were expanded by adjusting for average monthly glycemic burden (AMGB) and hypoglycemic events because hyper- and hypoglycemia might moderate the association between metformin or sulfonylurea and incident dementia. ${ }^{20,21}$ The AMGB was calculated by first measuring the cumulative amount over time that $\mathrm{HbA}_{1 \mathrm{c}}$ was $>7.5 \% .{ }^{20,21}$ One unit of total glycemic burden represents 1 month in which $\mathrm{HbA}_{1 \mathrm{c}}$ was 1 percentage point greater than $7.5 \%$. Dividing the total glycemic burden by the number of months between the first $\mathrm{HbA}_{1 \mathrm{c}}$ measurement after metformin or sulfonylurea prescription fill and the last measurement before dementia or censor date results in the AMGB. Hypoglycemic events were defined according to previously reported ICD-9-CM codes. ${ }^{22}$

The proportional hazard assumption for each model was tested by examining a time-dependent interaction term of metformin or sulfonylurea and log follow-up time with weighted data, in which a significant $(P<.05)$ interaction term indicates different hazard trends over time. The assumption was met for white and African American patients. Analyses were performed with SAS version 9.4 (SAS Institute). An $\alpha$ level of .05 was considered to indicate statistical significance.

\section{RESULTS}

Overall, $85.7 \%$ of the cohort was white, and $14.3 \%$ was African American. Sample characteristics by race are listed in Table 1. Older age, male sex, and status currently married were more common among white patients, whereas low nSES, access to VHA health insurance only, and high health care use were more common among African American patients $(P<.001)$. Diabetic neuropathy, but not other T2DM complications, was more prevalent among white patients. African American patients had greater $\mathrm{HbA}_{1 \mathrm{c}}$ and creatinine values before metformin or sulfonylurea initiation $(P<.001)$. Obesity, hyperlipidemia, ischemic heart disease, congestive heart failure, atrial fibrillation, and vitamin B12 deficiency were all significantly more prevalent in white patients. Hypertension was significantly more prevalent in African American patients $(P<.001)$. The presence of PTSD, schizophrenia, nicotine dependence/smoking, or alcohol or illicit drug abuse/dependence was significantly more common among African American patients. Anxiety disorders were more common among white patients $(P<.001)$. Statin use was significantly more common among white patients, and 


\section{Table 1. Characteristics of African American and White VHA Patients Aged $\geq 50$ Years Who Received Either a New Metformin or a New Sulfonylurea Prescription Fill ( $N=73,761)$ (continued)}

\begin{tabular}{|c|c|c|c|}
\hline Covariate & $\begin{array}{c}\text { White } \\
(n=63,202)\end{array}$ & $\begin{array}{l}\text { African American } \\
\quad(n=10,559)\end{array}$ & $\begin{array}{c}P \\
\text { Value }\end{array}$ \\
\hline \multicolumn{4}{|l|}{ Psychiatric and substance comorbidities } \\
\hline Depression, no. (\%) & $18,165(28.7)$ & $2,946(27.9)$ & .077 \\
\hline PTSD, no. (\%) & $11,704(18.5)$ & $2,631(24.9)$ & $<.001$ \\
\hline Other anxiety, no. (\%) & $9,076(14.4)$ & $1,081(10.2)$ & $<.001$ \\
\hline Bipolar disorder, no. (\%) & $4,926(7.8)$ & $823(7.8)$ & .999 \\
\hline Schizophrenia, no. (\%) & $3,008(4.8)$ & $1,063(10.1)$ & $<.001$ \\
\hline Nicotine dependence/smoking, no. (\%) & $33,240(52.6)$ & $6,072(57.5)$ & $<.001$ \\
\hline Alcohol abuse/dependence, no. (\%) & $9,209(14.6)$ & $2,620(24.8)$ & $<.001$ \\
\hline Illicit drug abuse/dependence, no. (\%) & $3,988(6.3)$ & $2,012(19.1)$ & $<.001$ \\
\hline \multicolumn{4}{|l|}{ Other medications ${ }^{b}$} \\
\hline Statins, no. (\%) & $45,061(71.3)$ & $6,276(59.4)$ & $<.001$ \\
\hline Anticholinergics, no. (\%) & $28,035(44.4)$ & $5,243(49.7)$ & $<.001$ \\
\hline NSAIDs, no. (\%) & $34,581(54.7)$ & $6,794(64.3)$ & $<.001$ \\
\hline Antihypertensives, no. (\%) & $55,492(87.8)$ & $9,273(87.8)$ & .954 \\
\hline \multicolumn{4}{|c|}{$\begin{array}{l}\text { NSAID = nonsteroidal anti-inflammatory drug; PTSD = posttraumatic stress disorder; VHA = Veterans Health } \\
\text { Administration. }\end{array}$} \\
\hline \multicolumn{4}{|c|}{$\begin{array}{l}\text { a Other anxiety disorders = panic disorder, obsessive-compulsive disorder, social phobia, generalized anxiety } \\
\text { disorder, anxiety not otherwise specified. } \\
\text { b Other medications = sustained use before metformin or sulfonylurea (at least } 2 \text { fills in a } 6 \text {-month period). }\end{array}$} \\
\hline
\end{tabular}

ican patients aged 65 to 74 years after control for AMGB and no longer statistically significant for both races in this age group after control for hypoglycemic events.

\section{DISCUSSION}

In a cohort of 73,761 patients aged $\geq 50$ years, we observed that after balancing measured confounding factors, metformin use was associated with a significantly lower risk of dementia in African American patients. Among African Americans aged 50 to 64 years, metformin use was associated with a $40 \%$ lower risk of dementia, and among African American patients aged 65 to 74 years, metformin use was associated with a $29 \%$ lower risk of dementia. We also observed a modest association in white patients aged 65 to 74 years, with

ated with incident dementia among white patients (HR $=0.96 ; 95 \% \mathrm{CI}, 0.9-1.03)$ but was significantly associated with a lower risk of dementia in African American patients ( $\mathrm{HR}=0.73$; 95\% CI, 0.6-0.89). Race significantly modified the relation of metformin vs sulfonylurea and dementia such that there was a greater reduction of risk of dementia in African American patients compared with white patients $(P=.008)$. Adjusting for AMGB and hypoglycemic events in models 3 and 4, respectively, had little effect on HR values.

With respect to weighted data, the associations between metformin vs sulfonylurea use and incident dementia by age group within race are shown in Table 4. In model 1 (the primary study model), metformin vs sulfonylurea use was not associated with incident dementia in white or African American patients aged $\geq 75$ years. Among white patients, metformin vs sulfonylurea use was associated with a significantly lower risk of dementia in patients aged 65 to 74 years $(\mathrm{HR}=0.9 ; 95 \% \mathrm{CI}, 0.82-0.99)$ but not among patients aged 50 to 64 years $(\mathrm{HR}=0.94 ; 95 \% \mathrm{CI}, 0.81-1.09)$. Among African American patients, there was a lower risk of dementia in patients aged 65 to 74 years $(\mathrm{HR}=0.71 ; 95 \% \mathrm{CI}, 0.53-0.94)$ and aged 50 to 64 years $(\mathrm{HR}=0.6 ; 95 \% \mathrm{CI}, 0.45-0.81)$. After adjusting for AMGB or hypoglycemic events, there was little change in HR values (models 2 and 3), however, the association between metformin and lower risk of dementia was no longer statistically significant for African Amer- a $10 \%$ lower risk, but no association for the other 2 age groups considered.

We observed no association between metformin use, compared with sulfonylurea use, and incident dementia among patients aged $\geq 75$ years, consistent with Orkaby and colleagues ${ }^{\prime 11}$ study of the association between 2 or more years of continuous metformin use compared with 2 or more years of continuous sulfonylurea use and risk of dementia. Our analysis revealed that white patients aged 65 to 74 years had a significant, modest, lower risk of dementia, similar to that observed by Orkaby and colleagues. ${ }^{11}$ Among African Americans aged 65 to 74 years, we observed a significant association between metformin use and lower risk of dementia, whereas Orkaby and colleagues ${ }^{11}$ reported no association in this age group. However, the overlapping CIs suggest point estimates from these studies are not necessarily inconsistent. Differences in the magnitude of association might be explained by the prior study's eligibility criteria, which included 2 years of continuous metformin or sulfonylurea use. This criterion might decrease variability between white and African American patients and metformin and sulfonylurea use, thereby making it difficult to detect differences by race in the association between metformin use and dementia. Additional studies are warranted to investigate the association between metformin adherence vs nonadherence and incident dementia. 
Table 2. Characteristics of Patients Who Received Either a New Metformin or a New Sulfonylurea Prescription Fill, Stratified by Race $(\mathrm{N}=73,761)$

\begin{tabular}{|c|c|c|c|c|c|c|}
\hline \multirow[b]{2}{*}{ Covariate } & \multicolumn{3}{|c|}{ White $(n=63,202)$} & \multicolumn{3}{|c|}{ African American $(n=10,559)$} \\
\hline & $\begin{array}{c}\text { Metformin } \\
(n=47,821)\end{array}$ & $\begin{array}{l}\text { Sulfonylurea } \\
(\mathrm{n}=15,381)\end{array}$ & $\begin{array}{c}P \\
\text { Value }\end{array}$ & $\begin{array}{l}\text { Metformin } \\
(n=8,038)\end{array}$ & $\begin{array}{c}\text { Sulfonylurea } \\
(n=2,521)\end{array}$ & $\begin{array}{c}P \\
\text { Value }\end{array}$ \\
\hline \multicolumn{7}{|l|}{ Index year, no. (\%) } \\
\hline $2002-2004$ & $2,274(4.8)$ & $1,379(9.0)$ & & $286(3.6)$ & $200(7.9)$ & \\
\hline $2005-2006$ & $13,899(29.1)$ & $6,829(44.4)$ & & $2,209(27.5)$ & $1,041(41.3)$ & \\
\hline $2007-2008$ & $12,999(27.2)$ & $3,715(24.2)$ & $<.001$ & $2,034(25.3)$ & $602(23.9)$ & $<.001$ \\
\hline $2009-2010$ & $10,805(22.6)$ & $2,211(14.4)$ & & $1,948(24.2)$ & $433(17.2)$ & \\
\hline $2011-2012$ & $7,844(16.4)$ & $1,247(8.1)$ & & $1,561(19.4)$ & $245(9.7)$ & \\
\hline \multicolumn{7}{|l|}{ Sociodemographic related } \\
\hline Age, $y$, mean $( \pm S D)$ & $60.4( \pm 8.1)$ & $64.1( \pm 9.4)$ & $<.001$ & $57.6( \pm 7.0)$ & $59.9( \pm 8.5)$ & $<.001$ \\
\hline \multicolumn{7}{|l|}{ Age category, y, no. (\%) } \\
\hline $50-64$ & $32,914(68.8)$ & $7,897(51.3)$ & & $6,543(81.4)$ & $1,782(70.7)$ & \\
\hline $65-74$ & $11,633(24.3)$ & $4,781(31.1)$ & $<.001$ & $1,276(15.9)$ & $548(21.7)$ & $<.001$ \\
\hline$\geq 75$ & $3,274(6.8)$ & $2,703(17.6)$ & & $219(2.7)$ & $191(7.6)$ & \\
\hline Male sex, no. (\%) & $46,352(96.9)$ & $15,001(97.5)$ & .0001 & $7,603(94.6)$ & $2,446(97.0)$ & $<.001$ \\
\hline Married, no. (\%) & $29,057(60.8)$ & $9,492(61.7)$ & .036 & $3,888(48.4)$ & $1,174(46.6)$ & .114 \\
\hline Low nSES, no. (\%) & $22,544(47.1)$ & $7,590(49.3)$ & $<.001$ & $5,171(64.3)$ & $1,694(67.2)$ & .009 \\
\hline VHA insurance only, no. (\%) & $21,703(45.4)$ & $6,002(39.0)$ & $<.001$ & $4,626(57.6)$ & $1,418(56.2)$ & .248 \\
\hline High health care use, no. (\%) & $11,500(24.0)$ & $3,878(25.2)$ & .003 & $2,353(29.3)$ & $781(31.0)$ & .102 \\
\hline \multicolumn{7}{|l|}{ Diabetes related } \\
\hline Diabetic nephropathy, no. (\%) & $506(1.1)$ & $247(1.6)$ & $<.001$ & $89(1.1)$ & $43(1.7)$ & .018 \\
\hline Diabetic retinopathy, no. (\%) & $2,267(4.7)$ & $1,008(6.6)$ & $<.001$ & $393(4.9)$ & $167(6.6)$ & .001 \\
\hline Diabetic neuropathy, no. (\%) & $3,332(7.0)$ & $1,364(8.9)$ & $<.001$ & $433(5.4)$ & $185(7.3)$ & .0003 \\
\hline $\mathrm{HbA}_{1 \mathrm{c}}$ value, $\%$, mean $( \pm \mathrm{SD})$ & $7.1( \pm 1.3)$ & $7.4( \pm 1.5)$ & $<.001$ & $7.4( \pm 1.6)$ & $7.7( \pm 1.9)$ & $<.001$ \\
\hline \multicolumn{7}{|l|}{$\mathrm{HbA}_{1 \mathrm{c}}$ category, no. (\%) } \\
\hline$<7 \%$ & $25,738(53.8)$ & $7,157(46.5)$ & & $3,891(48.4)$ & $984(39.0)$ & \\
\hline $7-8 \%$ & $14,519(30.4)$ & $4,920(32.0)$ & $<.001$ & $2,598(32.3)$ & $833(33.0)$ & $<.001$ \\
\hline$>8 \%$ & $7,564(15.8)$ & $3,304(21.5)$ & & $1,549(19.3)$ & $704(27.9)$ & \\
\hline Creatinine value, $\mathrm{mg} / \mathrm{dL}$, mean $( \pm S D)$ & $1.0( \pm 0.2)$ & $1.1( \pm 0.2)$ & $<.001$ & $1.0( \pm 0.2)$ & $1.1( \pm 0.2)$ & $<.001$ \\
\hline \multicolumn{7}{|l|}{ Other comorbidities } \\
\hline Obesity, no. (\%) & $30,193(63.1)$ & $8,023(52.2)$ & $<.001$ & $4,684(58.3)$ & $1,162(46.1)$ & $<.001$ \\
\hline Hypertension, no. (\%) & $43,223(90.4)$ & $14,103(91.7)$ & $<.001$ & $7,427(92.4)$ & $2,324(92.2)$ & .726 \\
\hline Hyperlipidemia, no. (\%) & $42,570(89.0)$ & $13,348(86.8)$ & $<.001$ & $6,417(79.8)$ & $1,835(72.8)$ & $<.001$ \\
\hline Stroke, no. (\%) & $3,029(6.3)$ & $1,275(8.3)$ & $<.001$ & $489(6.1)$ & $207(8.2)$ & .0002 \\
\hline Ischemic heart disease, no. (\%) & $22,979(48.1)$ & $8,535(55.5)$ & $<.001$ & $2,851(35.5)$ & $977(38.8)$ & .003 \\
\hline Congestive heart failure, no. (\%) & $7,797(16.3)$ & $3,812(24.8)$ & $<.001$ & $989(12.3)$ & $408(16.2)$ & $<.001$ \\
\hline Atrial fibrillation, no. (\%) & $6,158(12.9)$ & $2,933(19.1)$ & $<.001$ & $504(6.3)$ & $195(7.7)$ & .01 \\
\hline Traumatic brain injury, no. (\%) & $3,045(6.4)$ & $948(6.2)$ & .366 & $489(6.1)$ & $149(5.9)$ & .75 \\
\hline Vitamin B12 deficiency, no. (\%) & $2,370(5.0)$ & $873(5.7)$ & .0004 & $292(3.6)$ & $85(3.4)$ & .538 \\
\hline \multicolumn{7}{|l|}{ Psychiatric and substance comorbidities } \\
\hline Depression, no. (\%) & $14,231(29.8)$ & $3,934(25.6)$ & $<.001$ & $2,334(29.0)$ & $612(24.3)$ & $<.001$ \\
\hline PTSD, no. (\%) & 9,357 (19.6) & $2,347(15.3)$ & $<.001$ & $2,089(26.0)$ & $542(21.5)$ & $<.001$ \\
\hline Other anxiety, no. (\%) & $7,022(14.7)$ & $2,054(13.4)$ & $<.001$ & $847(10.5)$ & $234(9.3)$ & .07 \\
\hline Bipolar disorder, no. (\%) & $3,909(8.2)$ & $1,017(6.6)$ & $<.001$ & $650(8.1)$ & $173(6.9)$ & .045 \\
\hline Schizophrenia, no. (\%) & $2,335(4.9)$ & $673(4.4)$ & .01 & $809(10.1)$ & $254(10.1)$ & .988 \\
\hline Nicotine abuse/dependence, no. (\%) & $25,423(53.2)$ & $7,817(50.8)$ & $<.001$ & $4,630(57.6)$ & $1,442(57.2)$ & .722 \\
\hline Alcohol abuse/dependence, no. (\%) & $7,190(15.0)$ & $2,019(13.1)$ & $<.001$ & $2,008(25.0)$ & $612(24.3)$ & .474 \\
\hline Illicit drug abuse/dependence, no. (\%) & $3,139(6.6)$ & $849(5.5)$ & $<.001$ & $1,524(19.0)$ & $488(19.4)$ & .658 \\
\hline \multicolumn{7}{|l|}{ Other medications ${ }^{b}$} \\
\hline Statins, no. (\%) & $34,418(72.0)$ & $10,643(69.2)$ & $<.001$ & $4,896(60.9)$ & $1,380(54.7)$ & $<.001$ \\
\hline Anticholinergics, no. (\%) & $21,443(44.8)$ & $6,592(42.9)$ & $<.001$ & $4,035(50.2)$ & $1,208(47.9)$ & .046 \\
\hline NSAIDs, no. (\%) & $26,919(56.3)$ & $7,662(49.8)$ & $<.001$ & $5,272(65.6)$ & $1,522(60.4)$ & $<.001$ \\
\hline Antihypertensives, no. (\%) & $41,827(87.5)$ & $13,665(88.8)$ & $<.001$ & $7,057(87.8)$ & $2,216(87.9)$ & .887 \\
\hline
\end{tabular}




\section{Figure 2a. Covariate standardized mean difference (SMD), metformin vs sulfonylurea, white race.}

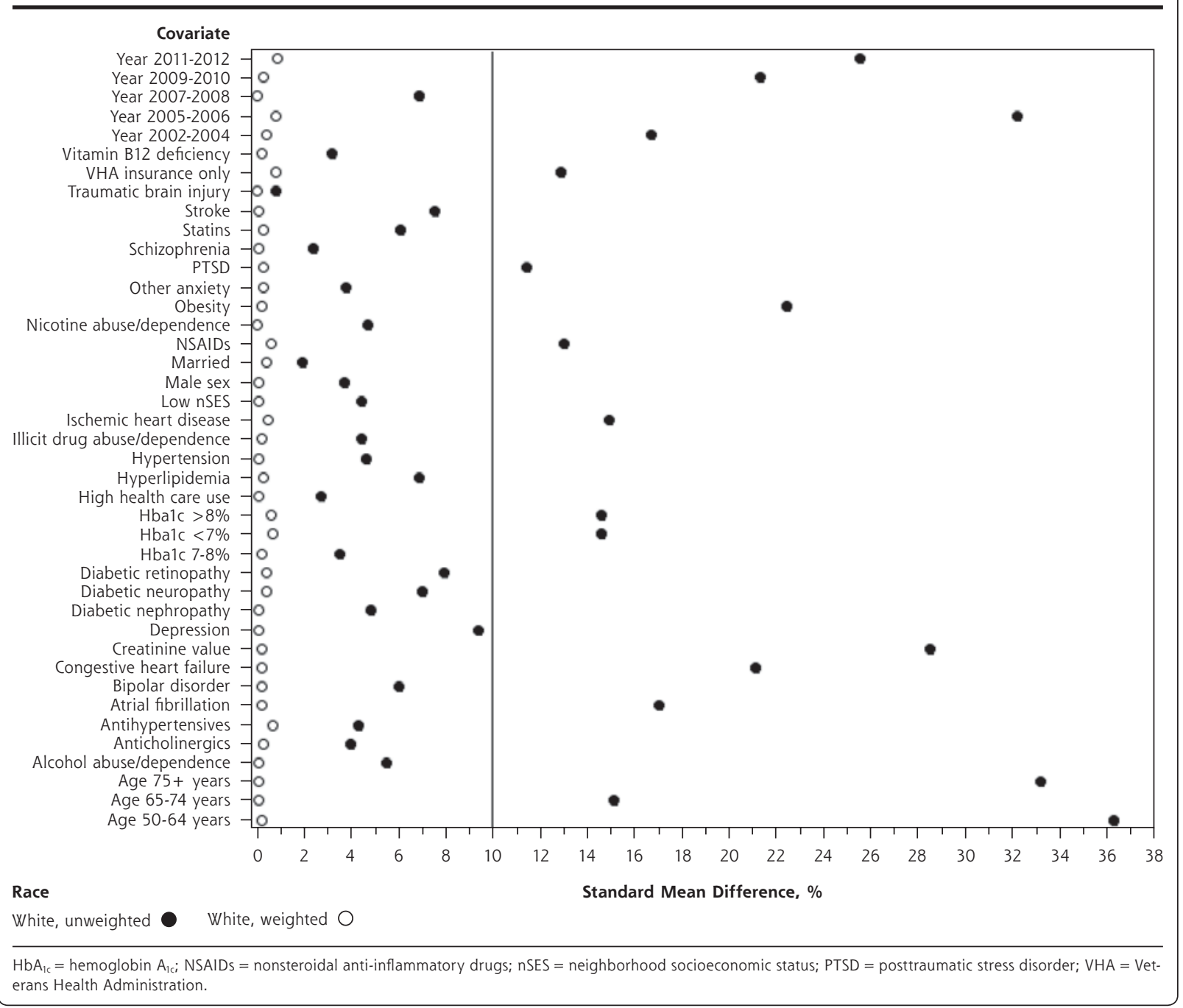

Miniscule changes in the magnitude of association between metformin use and incident dementia were observed after adjusting for AMGB and hypoglycemic events. Thus, it is unlikely that our results can be explained by greater decreases in $\mathrm{HbA}_{1 \mathrm{c}}$ after metformin use in African American patients compared with white patients. ${ }^{23,24}$ It is more likely that the mechanism underlying greater risk of dementia in patients with T2DM is multifactorial and not explained solely by glycemic control. ${ }^{25}$ Compared with white patients, African American patients are more likely to experience vascular dementia, have a greater prevalence of cardiovascular disease preceding dementia ${ }_{1}^{8}$ and have more systemic inflammation. ${ }^{26}$ Some evidence indicates that treatment with metformin vs alternative medications reduces the risk of cardiovascular disease and stroke ${ }^{26}$ and has direct anti-inflammatory effects. ${ }^{27}$ Thus, our present results could be due to an effect of metformin to reduce vascular disease and chronic inflammation in African American patients.

Compared with white patients, African American patients were younger ${ }_{i}$ more often in a lower nSES, likely to have a diagnosis of hyperlipidemia, ischemic heart disease, or atrial fibrillation; and more likely to have PTSD or illicit drug abuse/dependence. Though speculative, it is possible that metformin's association with dementia differs in patients with 1 , or a combination of many, of these demographic and clinical characteristics. Future research is needed to identify the demographic and clinical subgroups for whom metformin is most strongly associated with a decreased risk of dementia.

Several limitations should be considered. Using ICD-9-CM codes might lead to under-ascertainment of some conditions including dementia and hypoglycemia; one reason is that many diagnoses might 
Figure $2 \mathrm{~b}$. Covariate standardized mean difference (SMD), metformin vs sulfonylurea, African American race.

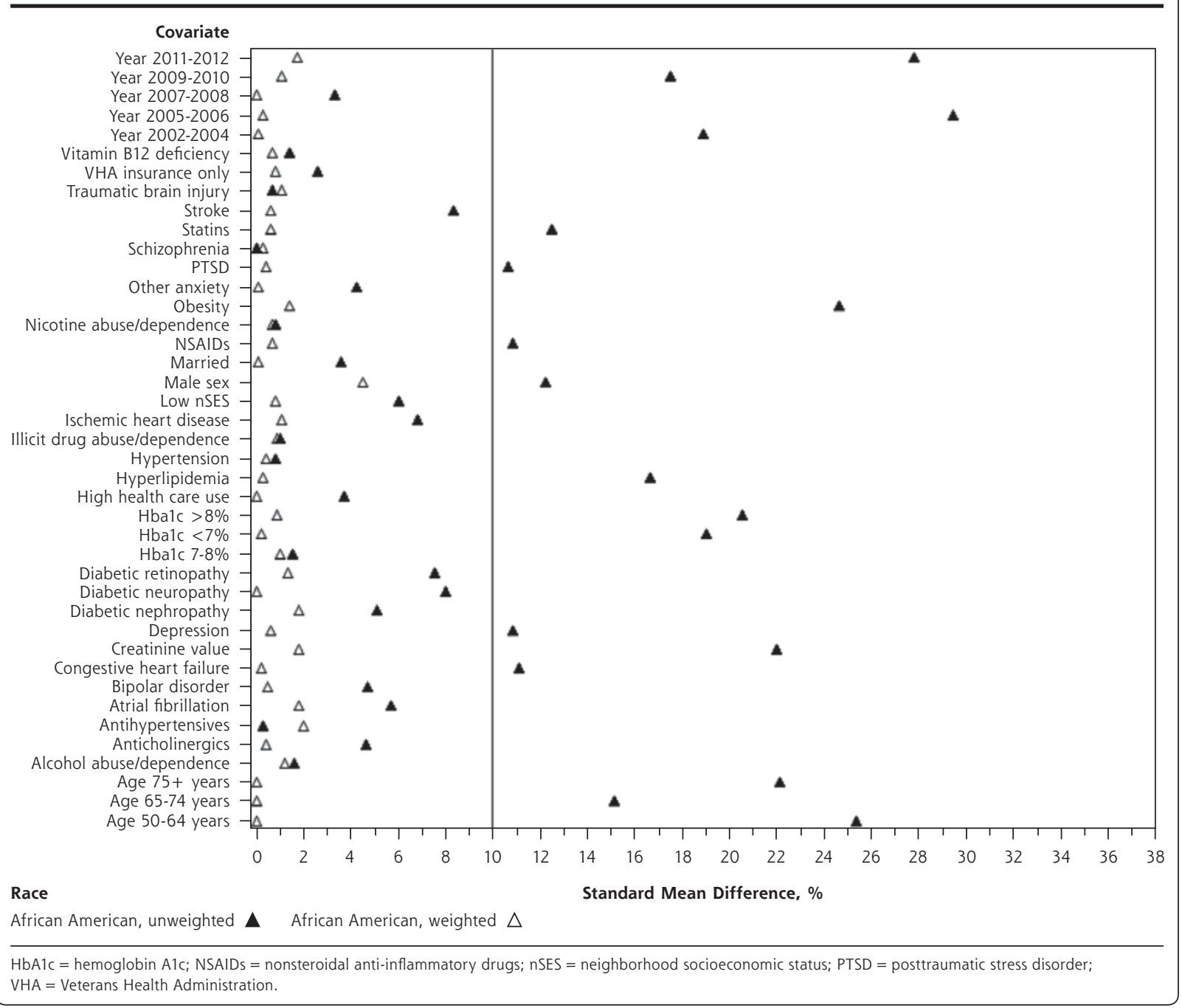

Table 3. Results From Cox Proportional Hazards Models Estimating the Association Between Receipt of a New Metformin vs a New Sulfonylurea Prescription Fill and Incident Dementia for FY 2002 to 2015, Stratified by Race, Among African American and White VHA Patients Aged $\geq 50$ Years $(\mathrm{N}=73,761)$

\begin{tabular}{|c|c|c|c|c|}
\hline & $\begin{array}{l}\text { Model } 1 \\
\text { Crude }^{a}\end{array}$ & $\begin{array}{l}\text { Model } 2 \\
\text { Weighted }^{b}\end{array}$ & $\begin{array}{l}\text { Model } 3 \\
\text { Weighted + AMGBc }\end{array}$ & $\begin{array}{c}\text { Model } 4 \\
\text { Weighted + Hypoglycemiad }^{\text {Mypog }}\end{array}$ \\
\hline Race & MET vs SU, HR (95\% Cl) & MET vs SU, HR (95\% Cl) & MET vs SU, HR (95\% Cl) & MET vs SU, HR (95\% Cl) \\
\hline White & $0.67(0.63-0.71)$ & $0.96(0.9-1.03)$ & $0.92(0.86-0.99)$ & $0.98(0.92-1.05)$ \\
\hline African Americane & $0.6(0.51-0.71)$ & $0.73(0.6-0.89)$ & $0.72(0.58-0.88)$ & $0.77(0.64-0.94)$ \\
\hline Race * drug, $P$ value ${ }^{f}$ & .207 & .008 & .026 & .022 \\
\hline \multicolumn{5}{|c|}{$\begin{array}{l}\mathrm{AMGB}=\text { average monthly glycemic burden; } \mathrm{FY}=\text { fiscal year; } \mathrm{HbA}_{\mathrm{lc}}=\text { hemoglobin } \mathrm{A}_{1 \mathrm{c}} ; \mathrm{HR}=\text { hazard ratio; } \mathrm{MET}=\text { metformin; SU = sulfonylurea; } \mathrm{VHA}=\mathrm{Veterans} \text { Health } \\
\text { Administration. }\end{array}$} \\
\hline \multicolumn{5}{|l|}{ a Unweighted data. } \\
\hline \multicolumn{5}{|c|}{ b Inverse probability of treatment weighted data with robust, sandwich-type variance estimators. } \\
\hline \multirow{2}{*}{\multicolumn{5}{|c|}{$\begin{array}{l}\text { 'Additional adjustment for glycemic burden from MET/SU initiation to end of follow-up among a subset of } 69,918 \text { African American and white VHA patients with at } \\
\text { least } 2 \mathrm{HbA}_{1 \mathrm{c}} \text { values after MET/SU initiation. }\end{array}$}} \\
\hline & & & & \\
\hline \multicolumn{5}{|c|}{$\begin{array}{l}\text { Additional adjustment for time-dependent hypoglycemia episode after MET/SU initiation. } \\
\text { e Proportional hazard assumption } P \text { value: } \text { white }=.244 ; \text { African American }=.07 \text {. }\end{array}$} \\
\hline
\end{tabular}




\section{Table 4. Association Between a New Metformin vs a New Sulfonylurea Prescription Fill and Incident Dementia for FY 2002 to 2015, Stratified by Age Within Race Group, Among African American and White VHA Patients Aged $\geq 50$ Years $(\mathrm{N}=73,761)$}

\begin{tabular}{lccc}
\hline & $\begin{array}{c}\text { Model 1 } \\
\text { Cox Model } \\
\text { Weighted }\end{array}$ & $\begin{array}{c}\text { Model 2 } \\
\text { Cox Model } \\
\text { Weighted + AMGB }\end{array}$ & $\begin{array}{c}\text { Model 3 } \\
\text { Cox Model } \\
\text { Weighted + Hypoglycemia }\end{array}$ \\
\hline White race & MET vs SU, HR (95\% CI) & MET vs SU, HR (95\% CI) & MET vs SU, HR (95\% CI) \\
$50-64$ years of age & $0.94(0.81-1.09)$ & $0.93(0.8-1.09)$ & $0.97(0.84-1.13)$ \\
$65-74$ years of age & $0.9(0.82-0.99)$ & $0.89(0.8-0.99)$ & $0.92(0.84-1.02)$ \\
$\geq 75$ years of age & $1.01(0.91-1.13)$ & $1.01(0.89-1.14)$ & $1.03(0.92-1.15)$ \\
Age * drug, $P$ value & .315 & .314 & .351 \\
African American race & MET vs SU, HR (95\% CI) & MET vs SU, HR (95\% CI) & MET vs SU, HR (95\% CI) \\
$50-64$ years of age & $0.6(0.45-0.81)$ & $0.56(0.41-0.77)$ & $0.63(0.47-0.85)$ \\
$65-74$ years of age & $0.71(0.53-0.94)$ & $0.79(0.58-1.08)$ & $0.77(0.57-1.03)$ \\
$\geq 75$ years of age & $1.17(0.73-1.85)$ & $1.18(0.7-1.98)$ & $1.39(0.83-2.36)$ \\
Age * drug, $P$ value & .055 & .038 & .036 \\
\hline
\end{tabular}

AMGB = average monthly glycemic burden from MET/SU start to end of follow-up; FY = fiscal year; HR = hazard ratio; hypoglycemia = time-dependent hypoglycemia episode from MET/SU start to end of follow-up; MET = metformin; SU = sulfonylurea; VHA = Veterans Health Administration.

compete for recognition and documentation during a busy visit with a complex patient. We designed our diagnostic algorithms to maximize positive predictive value, but it is possible that true dementia cases were misclassified as noncases. This error would bias our results to the null, on average. Results might not generalize to non-VHA patient populations. Although we controlled for many potential confounding variables, residual confounding might be present. Finally, psychosocial determinants of health, such as social support, are not available in medical record data but could influence the association between metformin use and dementia. We are unable to draw definitive conclusions regarding cause and effect, and clinical trials are necessary to confirm the hypothesis that metformin use is associated with a reduced risk of dementia and confirm that the magnitude of the association is greater in African American compared with white patients with T2DM.

There are no existing medications to prevent dementia. The $29 \%$ decreased risk of dementia associated with metformin use in African American patients aged 65 to 74 years and the $40 \%$ decreased risk in those aged 50 to 64 years suggest that someday this inexpensive, widely available treatment could be broadly prescribed to substantially reduce the risk of dementia in younger African American patients with T2DM.

To read or post commentaries in response to this article, see it online at http://www.AnnFamMed.org/content/17/4/352.

Submitted January 3, 2019; submitted, revised, March 8, 2019; accepted March 26, 2019.

Key words: metformin; diabetes; dementia; medical records; epidemiology
Funding support: This research was supported by R21AG055604, A Big Data Research Study on the Relationship Between Metformin Use and Dementia. Support for VA/CMS data was provided by the Department of Veterans Affairs, Veterans Health Administration, Office of Research and Development, Health Services Research and Development, VA Information Resource Center (Project Numbers SDR02-237 and 98-004). This material is the result of work supported with resources and the use of facilities at the Harry S. Truman Memorial Veterans' Hospital.

Disclaimer: The views expressed do not necessarily reflect those of the Veterans Health Administration.

Author contributions: Dr Scherrer and Ms Salas had full access to Veterans Health Administration data. Dr Scherrer had final responsibility for the decision to submit for publication.

Supplementary materials: Available at http://www.AnnFamMed. org/content/17/4/352/suppl/DC1/

\section{References}

1. American Diabetes Association. http://www.diabetes.org/diabetesbasics/statistics/. Accessed May 4, 2016.

2. El-Kebbi IM, Cook CB, Ziemer DC, Miller CD, Gallina DL, Phillips LS. Association of younger age with poor glycemic control and obesity in urban African Americans with type 2 diabetes. Arch Intern Med. 2003;163(1):69-75.

3. Campbell JA, Walker RJ, Smalls BL, Egede LE. Glucose control in diabetes: the impact of racial differences on monitoring and outcomes. Endocrine. 2012;42(3):471-482.

4. de Rekeneire N, Rooks RN, Simonsick EM, et al; Health, Aging and Body Composition Study. Racial differences in glycemic control in a well-functioning older diabetic population: findings from the Health, Aging and Body Composition Study. Diabetes Care. 2003; 26(7):1986-1992.

5. Chatterjee S, Peters SA, Woodward M, et al. Type 2 diabetes as a risk factor for dementia in women compared with men: a pooled analysis of 2.3 million people comprising more than 100,000 cases of dementia. Diabetes Care. 2016;39(2):300-307.

6. Steenland K, Goldstein FC, Levey A, Wharton W. A meta-analysis of Alzheimer's disease incidence and prevalence comparing AfricanAmericans and Caucasians. J Alzheimers Dis. 2016;50(1):71-76. 
7. Potter GG, Plassman BL, Burke JR, et al. Cognitive performance and informant reports in the diagnosis of cognitive impairment and dementia in African Americans and whites. Alzheimers Dement. 2009;5(6):445-453.

8. Lines LM, Wiener JM. Racial and Ethnic Disparities in Alzheimer's Disease: A Literature Review. Washington, DC: US Dept of Health and Human Services; 2014. Contract \#HHSP23320100021WI.

9. Mayeda ER, Karter AJ, Huang ES, Moffet HH, Haan MN, Whitmer RA. Racial/ethnic differences in dementia risk among older type 2 diabetic patients: the diabetes and aging study. Diabetes Care. 2014; 37(4):1009-1015.

10. Mayeda ER, Haan MN, Neuhaus J, et al. Type 2 diabetes and cognitive decline over 14 years in middle-aged African Americans and whites: the ARIC Brain MRI Study. Neuroepidemiology. 2014;43(3-4): 220-227.

11. Orkaby AR, Cho K, Cormack J, Gagnon DR, Driver JA. Metformin vs sulfonylurea use and risk of dementia in US veterans aged $\geq 65$ years with diabetes. Neurology. 2017;89(18):1877-1885.

12. Scherrer JF, Salas J, Floyd JS, Farr SA, Morley JE, Dublin S. Metformin and sulfonylurea use and risk of incident dementia. Mayo Clin Proc. In press; 2019.

13. Nguyen QM, Xu JH, Chen W, Srinivasan SR, Berenson GS. Correlates of age onset of type 2 diabetes among relatively young black and white adults in a community: the Bogalusa Heart Study. Diabetes Care. 2012;35(6):1341-1346.

14. Zilkens RR, Bruce DG, Duke J, Spilsbury K, Semmens JB. Severe psychiatric disorders in mid-life and risk of dementia in late-life (age 65-84 years): a population based case-control study. Curr Alzheimer Res. 2014;11(7):681-693.

15. Roblin DW. Validation of a neighborhood SES index in a managed care organization. Med Care. 2013;51(1):e1-e8.

16. Curtis LH, Hammill BG, Eisenstein EL, Kramer JM, Anstrom KJ. Using inverse probability-weighted estimators in comparative effectiveness analyses with observational databases. Med Care. 2007; 45(10 Supl 2):S103-S107.
17. Rosenbaum PR, Rubin DB. The central role of the propensity score in observational studies for causal effects. Biometrika Trust. 1983; 70(1):41-55.

18. Austin PC, Stuart EA. Moving towards best practice when using inverse probability of treatment weighting (IPTW) using the propensity score to estimate causal treatment effects in observational studies. Stat Med. 2015;34(28):3661-3679.

19. Austin PC. Balance diagnostics for comparing the distribution of baseline covariates between treatment groups in propensity-score matched samples. Stat Med. 2009;28(25):3083-3107.

20. Nichols GA, Rosales AG, Perrin NA, Fortmann SP. The association between different A1C-based measures of glycemia and risk of cardiovascular disease hospitalization. Diabetes Care. 2014;37(1): 167-172.

21. Brown JB, Nichols GA, Perry A. The burden of treatment failure in type 2 diabetes. Diabetes Care. 2004;27(7):1535-1540.

22. Ginde AA, Blanc PG, Lieberman RM, Camargo CA Jr. Validation of ICD-9-CM coding algorithm for improved identification of hypoglycemia visits. BMC Endocr Disord. 2008;8:4.

23. Zhang C, Zhang R. More effective glycaemic control by metformin in African Americans than in Whites in the prediabetic population. Diabetes Metab. 2015;41(2):173-175.

24. Williams LK, Padhukasahasram B, Ahmedani BK, et al. Differing effects of metformin on glycemic control by race-ethnicity. J Clin Endocrinol Metab. 2014;99(9):3160-3168.

25. Morley JE. Diabetes: the diabetic brain. Nat Rev Endocrinol. 2017; 13(10):570-571

26. Stepanikova I, Bateman LB, Oates GR. Systemic inflammation in midlife: race, socioeconomic status, and perceived discrimination. Am J Prev Med. 2017;52(1S1):S63-S76.

27. Saisho Y. Metformin and inflammation: its potential beyond glucose-lowering effect. Endocr Metab Immune Disord Drug Targets. 2015;15(3):196-205. 